\title{
Clinical outcome of patients with stable ischaemic heart disease as compared to those with acute coronary syndromes after percutaneous coronary intervention
}

\author{
Pascal Vranckx ${ }^{1,3,6}$, MD, PhD; Bindu Kalesan ${ }^{2}$, MSc; Giulio G. Stefanini ${ }^{4}$, MD; Vasim Farooq ${ }^{3}$, MBChB; $^{2}$ \\ Yoshinobu Onuma ${ }^{3}$, MD; Sigmund Silber ${ }^{5}$, MD; Ton de Vries ${ }^{6}$, MSc; Peter Jüni ${ }^{2,7}$, MD; \\ Patrick W. Serruys ${ }^{3 *}$, MD, PhD; Stephan Windecker ${ }^{4,7}, \mathrm{MD}$ \\ 1. Department of Cardiac Intensive Care \& Interventional Cardiology, Hartcentrum, Hasselt, Belgium; 2. Institute of Social and \\ Preventive Medicine, University of Bern, Bern, Switzerland; 3. Department of Cardiology, Thoraxcenter, Erasmus MC, \\ Rotterdam, The Netherlands; 4. Department of Cardiology, Bern University Hospital, Bern, Switzerland; 5. Heart Center at the \\ Isar, Munich, Germany; 6. Cardialysis Clinical Research Management \& Core Laboratories, Rotterdam, The Netherlands; \\ 7. Clinical Trials Unit, Bern University Hospital, Bern, Switzerland
}

GUEST EDITOR: Ron Waksman, MD; Interventional Cardiology, MedStar Washington Hospital Center, Washington, DC, USA

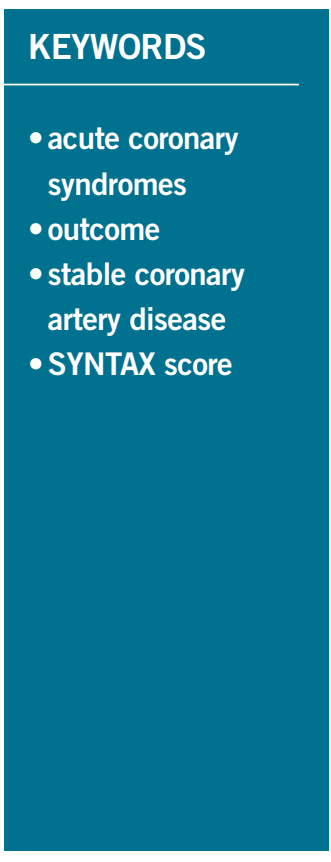

\begin{abstract}
Aims: To compare clinical outcomes after percutaneous coronary intervention (PCI) between patients with acute coronary syndromes (ACS) and those with stable ischaemic heart disease (SIHD) stratified by anatomic disease complexity (SYNTAX score).

Methods and results: Patient-level data from three all-comers PCI trials were pooled. Patients $(\mathrm{n}=4,204)$ were stratified by clinical presentation (i.e., ACS or SIHD) and by SYNTAX score (i.e., lowest vs. two highest tertiles). The major adverse cardiac event (MACE) rates of patients with low-risk SIHD ( $n=531)$ and high-risk SIHD $(n=1,066)$ were compared with ACS patients $(n=2,607)$, respectively. At two years, the risk of MACE was higher for high-risk SIHD patients (OR 1.34, 95\% CI: 1.08-1.66) and lower for low-risk SIHD patients (OR 0.61, 95\% CI: 0.43-0.87) compared with ACS patients, respectively. This difference between high-risk SIHD patients and ACS patients was primarily driven by a higher risk of myocardial infarction (OR $1.64,95 \%$ CI: $1.21-2.21$ ), while there was no difference for cardiac death (OR $0.77,95 \%$ CI: $0.49-1.21$ ) or target lesion revascularisation (OR 1.21, 95\% CI: 0.91-1.62).
\end{abstract}

Conclusions: In this pooled analysis, the majority of patients undergoing PCI for SIHD (i.e., with SYNTAX score $>8$ ) had a higher risk of MACE than patients with ACS. Trial registration: URL: http://www.ClinicalTrials.gov; unique identifier: NCT00297661 (Sirtax), NCT00389220 (Leaders), NCT00114972 (Resolute-AC).

\footnotetext{
*Corresponding author: Ba583a, Thoraxcenter, Erasmus MC, 's-Gravendijkwal 230, 3015 CE Rotterdam, The Netherlands. E-mail:p.w.j.c.serruys@erasmusmc.nl
} 


\section{Introduction}

Treatment of obstructive coronary lesions causing ischaemia by means of percutaneous coronary intervention (PCI) with stent implantation improves functional status and clinical outcomes ${ }^{1-4}$. The expanding indications for PCI, coupled with refinements in technology, including the introduction of drug-eluting stents (DES) and more intensive adjunctive pharmacological treatment, have resulted in the treatment of increasingly complex lesions and patients with a history of established cardiovascular disease, coexisting morbidities, and complex coronary anatomy in recent years ${ }^{5-7}$. Complex lesions and patient subsets were excluded from the initial coronary stent studies. More recently, however, large-scale investigations of stent technology have been performed in the context of so-called "all-comers" patient populations allowing the unrestricted use of DES ${ }^{8-11}$.

All-comers studies provide an opportunity to compare clinical outcomes among patients presenting with and without acute coronary syndromes (ACS) in the context of a randomised trial. Noteworthy, careful risk assessment based on clinical and angiographic characteristics is used to guide decision making regarding type of therapeutic intervention, triage among hospital care levels, and allocation of clinical resources ${ }^{12-14}$. Therefore, identification of higher-risk patients remains of paramount importance. Patients presenting with ACS are currently considered to be at high risk of major adverse cardiac events (MACE) during short- and long-term followup, and therefore receive aggressive pharmacotherapy ${ }^{15}$. However, patients with stable ischaemic heart disease (SIHD) include a broad spectrum of anatomic disease complexity, which - as assessed by the SYNTAX score - has been shown to be predictive of outcomes $^{16-18}$. To date, no data are available comparing outcomes after PCI between patients with ACS and stable CAD stratified by anatomic disease complexity. Against this background, we compared clinical outcomes between patients with ACS and those with SIHD stratified into high and low-risk cohorts according to the angiographic SYNTAX score.

\section{Methods \\ STUDY POPULATION}

Individual data were pooled for 5,011 patients from three large randomised clinical trials investigating the unrestricted use of DES for coronary revascularisation: the Sirolimus-Eluting and Paclitaxel-Eluting Stent for Coronary Revascularization (SIRTAX; $\mathrm{n}=1,012$ ) trial $^{9}$, the Biolimus-Eluting Stent with Biodegradable Polymer versus Sirolimus-Eluting Stent with Durable Polymer for Coronary Revascularisation (LEADERS; $\mathrm{n}=1,707$ ) trial $^{10}$, and the Comparison of Zotarolimus-Eluting and Everolimus-Eluting Coronary Stents (RESOLUTE AC; $n=2,292$ ) trial ${ }^{11}$. All trials were conducted between 2004 and 2009 at European institutions, with the unrestricted use of DES and an all-comers study design. Inclusion criteria were broad in order to reflect routine clinical practice. Patients with either stable coronary artery disease or acute coronary syndromes (including patients with unstable angina, non-ST-segment elevation and ST-segment elevation myocardial infarction) were eligible, if they had at least one lesion with diameter stenosis of $50 \%$ or more in a vessel with reference diameter of 2.25 to $4.0 \mathrm{~mm}$ (SIRTAX and RESOLUTE all-comers) and 2.25 to $3.5 \mathrm{~mm}$ (LEADERS). None of the trials had any restriction with respect to number of treated lesions, treated vessels, lesion length, or number of stents implanted. Exclusion criteria were few and included known intolerance to the study drugs, metal alloys or contrast media, planned surgery within six months after the index procedure, and participation in another study. Angiographic follow-up was planned at eight months among patients included in SIRTAX, at nine months among $25 \%$ of patients included in LEADERS, and at 13 months among $20 \%$ of patients in RESOLUTE-AC. The angiographic SYNTAX score at baseline was determined in each of the trials. The trials complied with the provisions of the Declaration of Helsinki, and the study protocols were approved by the institutional review board at each study centre. All patients provided written informed consent for participation in the study.

\section{PROCEDURES}

Randomisation was done after diagnostic angiography and before PCI in all three trials. In the SIRTAX trial patients were randomly allocated to receive sirolimus-eluting stents $\left(\right.$ CYPHER $^{\circledR}$; Cordis, Johnson \& Johnson, Miami Lakes, FL, USA) or paclitaxel-eluting stents (TAXUSTM; Boston Scientific, Natick, MA, USA), in the LEADERS trial patients were randomly allocated to receive biolimus-eluting stents (BioMatrix ${ }^{\mathrm{TM}}$; Biosensors Inc., Newport Beach, CA, USA) or sirolimus-eluting stents (CYPHER ${ }^{\circledR}$; Cordis, Johnson \& Johnson), and in the RESOLUTE-AC trial patients were randomly allocated to receive zotarolimus-eluting stents (Endeavor ${ }^{\mathbb{B}}$ Resolute; Medtronic Inc., Santa Rosa, CA, USA) or everolimuseluting stents (XIENCE V ${ }^{\circledR}$; Abbott Vascular, Santa Clara, CA, USA). Balloon angioplasty and stent implantation were performed according to standard techniques and in accordance with guidelines; direct stenting was allowed. Full lesion coverage was attempted by implanting one or several stents. No mixture of types of stent was permitted for a given patient unless the operator was unable to insert the study stent, in which case crossover to another device of the operator's choice was possible. In case of unplanned revascularisation procedures requiring stent implantation, it was recommended that physicians use the same type as the initially allocated study stent. Procedural anticoagulation was achieved with unfractionated heparin at a dose of 5,000 IU or 70 to 100 IU per kilogram of body weight; the use of glycoprotein IIb/IIIa inhibitors was left to the operator's discretion. Dual antiplatelet therapy consisting of acetylsalicylic acid of at least $75 \mathrm{mg}$ once daily and the thienopyridine clopidogrel $75 \mathrm{mg}$ daily was prescribed for at least 12 months in SIRTAX and LEADERS, and for at least six months in the RESOLUTE-AC trial.

\section{DEFINITIONS}

The main outcome measure of the present study was the risk of MACE, defined as a composite of cardiac death, myocardial infarction (MI), and ischaemia-driven target lesion revascularisation 
(TLR). Secondary outcomes were the individual components of MACE as well as all-cause death, target vessel revascularisation, as well as definite and definite/probable stent thrombosis according to the Academic Research Consortium criteria ${ }^{19}$.

For each trial, a blinded clinical events committee independently adjudicated all adverse events. Endpoint definitions were comparable across the three trials. Cardiac death was defined as death from cardiac causes or any death from unknown causes in SIRTAX and LEADERS, and as any death unless an undisputed non-cardiac cause was present in RESOLUTE-AC. MI was defined - in the SIRTAX and LEADERS trials - as the presence of new Q-waves in at least two contiguous leads and an elevated creatine kinase MB fraction, or - in the absence of significant Q-waves - as an increase in the creatine kinase level to more than twice the upper limit of the normal range with an elevated level of creatine kinase MB or troponin ${ }^{9,10}$. In the RESOLUTE-AC trial MI was defined according to an "extended historical" definition consistent with the one used in SIRTAX and LEADERS ${ }^{20}$. Target lesion revascularisation was defined as any revascularisation for a stenosis within the stent or within a $5 \mathrm{~mm}$ border proximal and distal to the stent in all three trials. A revascularisation was considered ischaemia-driven in the presence of angiographic diameter stenosis of at least $50 \%$ and ischaemic signs or symptoms, or with angiographic diameter stenosis of at least $70 \%$ regardless of ischaemic signs or symptoms ${ }^{9-11}$.

The SYNTAX score for each patient was calculated prospectively by scoring all coronary lesions with a DS $\geq 50 \%$, in vessels $\geq 1.5 \mathrm{~mm}$, using the SYNTAX score algorithm which is described in full elsewhere ${ }^{16,21}$, and available at www.syntaxscore.com. All angiographic variables pertinent to SYNTAX score calculation were computed by two analysts from a core laboratory (Cardialysis B.V., Rotterdam, The Netherlands), blinded to clinical presentation and outcomes. In the event of disagreement, the opinion of a third analyst was sought, and the final decision was established by consensus. As previously described ${ }^{17,22-24}$, patients with occluded infarct-related arteries were scored as having occlusions of unknown duration in a similar manner to any chronically occluded artery. In addition, those patients with lesions due to restenosis were scored in the same manner as de novo lesions.

\section{STATISTICAL ANALYSIS}

From a total of 5,011 randomised patients, 4,204 (84\%) patients with a calculated preprocedural SYNTAX score completed two years of follow-up and were included in the present analysis. Patients were stratified according to baseline clinical presentation (i.e., ACS or SIHD). Patients with SIHD were further stratified by SYNTAX score (i.e., higher tertiles [SYNTAX score $>8$ ] or lower tertile [SYNTAX score $\leq 8])^{17}$. Clinical outcomes of patients with SIHD at low risk and at high risk were compared with patients with ACS, respectively. Clinical outcomes were compared overall, as well as according to a landmark analysis at 30 days and after stratification by gender. Mixed regression models were used with type of randomised clinical trial as the random intercept and treatment arms as the random coefficient. Percentages were predicted probabilities derived from mixed maximum logistic regression models for the categorical variables, whereas mean and standard deviations (SD) were predicted from the mixed likelihood regression models for the continuous covariates. All the odds ratios (OR) and 95\% confidence intervals (CI) were adjusted for stent type. Cumulative incidence curves were constructed using the Kaplan-Meier methodology and compared using the log-rank test. A sensitivity analysis was performed by excluding periprocedural MI, defined as any non-Q-wave MI occurring within 48 hours after PCI not associated with definite stent thrombosis. All analyses are by intention to treat, performed using STATA 11.2 (StataCorp LP, College Station, TX, USA).

\section{Results}

From a total of 4,204 patients, 2,607 (62\%) patients presented with ACS, 1,066 (25\%) patients with stable, high-risk coronary artery disease, and $531(13 \%)$ patients with stable, low-risk coronary artery disease. Baseline clinical characteristics of the three groups are summarised in Table 1. Low-risk SIHD patients were older $(p<0.0001)$, more likely to be female ( $\mathrm{p}=0.014)$, more frequently had hypertension $(\mathrm{p}<0.0001)$, hypercholesterolaemia, and previous PCI $(\mathrm{p}<0.0001)$, and less frequently had smoking habits $(\mathrm{p}<0.0001)$, previous coronary artery bypass grafting $(\mathrm{p}=0.028)$, multivessel disease $(\mathrm{p}<0.0001)$, and impaired left ventricular systolic function $(p<0.0001)$ compared with ACS patients. High-risk SIHD patients were older ( $<<0.0001)$, more frequently had diabetes mellitus $(\mathrm{p}<0.0001)$, hypertension $(\mathrm{p}<0.0001)$, hypercholesterolaemia $(\mathrm{p}<0.0001)$, previous MI $(\mathrm{p}<0.0001)$, previous PCI $(p<0.0001)$, multivessel disease $(p<0.0001)$, and less frequently had smoking habits $(\mathrm{p}<0.0001)$, previous coronary artery bypass grafting $(p<0.0001)$ and impaired left ventricular systolic function $(\mathrm{p}<0.0001)$, compared with ACS patients.

Angiographic and procedural characteristics are summarised in Table 2. Low-risk SIHD patients more frequently had the right coronary artery and less frequently a bypass graft as target lesion $(\mathrm{p}<0.0001)$, and less frequently had de novo lesions $(\mathrm{p}=0.006)$, moderately or severely calcified lesions $(\mathrm{p}=0.033)$, and total occlusions $(\mathrm{p}<0.0001)$, compared with ACS patients. Conversely, highrisk SIHD patients more frequently had the left anterior descending and less frequently a bypass graft as target vessel $(p<0.0001)$, more frequently had moderate or severe calcified lesions ( $p<0.0001)$, and less frequently had de novo lesions $(\mathrm{p}=0.01)$ and total occlusions $(\mathrm{p}<0.0001)$, compared with ACS patients.

Clinical outcomes up to two years are reported in Table 3, overall and according to a landmark analysis at 30 days. Cumulative incidence curves for MACE up to two years are shown in Figure 1. At two years, the risk of MACE was lower for low-risk SIHD patients (OR 0.61, 95\% CI: 0.43-0.87) and higher for high-risk SIHD patients (OR 1.34, 95\% CI: 1.08-1.66), respectively, compared with ACS patients. Low-risk SIHD patients had a markedly reduced risk of cardiac death (OR 0.22, 95\% CI: 0.08-0.59) and similar risks of MI (OR 0.85, 95\% CI: 0.52-1.38) and TLR (OR 0.66, 95\% CI: 0.42-1.03), compared with ACS patients.

The differences between high-risk SIHD and ACS patients were primarily driven by a higher risk of MI (OR 1.64, 95\% CI: 
Table 1. Baseline clinical characteristics.

\begin{tabular}{|c|c|c|c|c|c|c|c|}
\hline & \multirow{2}{*}{ Low-risk SIHD } & \multirow{2}{*}{ High-risk SIHD } & \multirow{2}{*}{ ACS } & \multicolumn{2}{|c|}{ Low-risk SIHD vs. ACS } & \multicolumn{2}{|c|}{ High-risk SIHD vs. ACS } \\
\hline & & & & Difference (95\% CI) & $p$ & Difference (95\% CI) & $p$ \\
\hline No. of patients & 531 & 1,066 & 2,607 & & & & \\
\hline Age & $64.6(9.9)$ & $65.3(10.4)$ & $62.8(11.3)$ & $1.9(0.9$ to 3.0$)$ & $<0.0001$ & 2.5 (1.8 to 3.3$)$ & $<0.0001$ \\
\hline Female & $154(29.0)$ & $261(24.5)$ & $624(23.9)$ & $5.1(1.0$ to 9.1$)$ & 0.014 & $0.5(-2.5$ to 3.6$)$ & 0.724 \\
\hline Diabetes & $120(22.6)$ & $285(26.7)$ & $516(19.8)$ & $2.8(-0.8$ to 6.4$)$ & 0.125 & 6.9 (4.0 to 9.9$)$ & $<0.0001$ \\
\hline Insulin-requiring diabetes & $45(37.5)$ & $84(29.5)$ & $179(34.7)$ & 2.8 (-6.7 to 12.3$)$ & 0.562 & $-5.2(-12.0$ to 1.6$)$ & 0.133 \\
\hline Obese & $157(29.6)$ & $257(24.2)$ & $663(25.6)$ & $4.0(0.1$ to 8.0$)$ & 0.046 & $-1.4(-4.6$ to 1.7$)$ & 0.375 \\
\hline Renal impairment (eGFR <60) & 76 (14.3) & $167(15.7)$ & $354(13.6)$ & 0.7 (-1.9 to 3.3$)$ & 0.579 & 2.1 (-0.4 to 4.5$)$ & 0.095 \\
\hline Hypertension & $395(74.4)$ & $799(75.0)$ & $1,719(65.9)$ & 8.5 (4.6 to 12.3 ) & $<0.0001$ & 9.0 (5.8 to 12.3$)$ & $<0.0001$ \\
\hline Hypercholesterolaemia & $381(71.8)$ & $757(71.0)$ & $1,505(57.7)$ & 14.0 (9.7 to 18.4$)$ & $<0.0001$ & 13.3 (9.8 to 16.7$)$ & $<0.0001$ \\
\hline Current smoking & $123(23.2)$ & $212(19.9)$ & $884(33.9)$ & $-10.8(-14.8$ to -6.7$)$ & $<0.0001$ & $-14.0(-17.3$ to -10.8$)$ & $<0.0001$ \\
\hline Previous MI & $149(28.2)$ & $343(32.6)$ & $691(26.7)$ & $1.5(-2.9$ to 6.0$)$ & 0.501 & 5.9 (2.7 to 9.2) & $<0.0001$ \\
\hline Previous PCl & $199(37.5)$ & $402(37.7)$ & $602(23.1)$ & 14.4 (10.6 to 18.2 ) & $<0.0001$ & 14.6 (11.5 to 17.8$)$ & $<0.0001$ \\
\hline Previous CABG & $22(4.1)$ & $16(1.5)$ & $182(7.0)$ & $-2.8(-5.4$ to -0.3$)$ & 0.028 & $-5.5(-7.3$ to -3.7$)$ & $<0.0001$ \\
\hline LVEF $<0.50$ & $55(13.0)$ & $109(14.5)$ & $479(27.2)$ & $-14.2(-18.9$ to -9.5$)$ & $<0.0001$ & $-12.7(-16.4$ to -8.9$)$ & $<0.0001$ \\
\hline Multivessel disease & $31(5.8)$ & $278(26.1)$ & $491(18.8)$ & $-13.0(-17.1$ to -8.9$)$ & $<0.0001$ & 7.3 (4.6 to 10.0$)$ & $<0.0001$ \\
\hline
\end{tabular}

1.21-2.21), whereas no differences were observed for cardiac death (OR 0.77, 95\% CI: 0.49-1.21) and TLR (OR 1.21, 95\% CI: 0.911.62). Landmark analyses showed that high-risk SIHD patients compared with ACS patients had an increased risk of MI during the first 30 days (OR 1.89, 95\% CI: 1.35-2.66) without differences beyond 30 days up to two years (OR $1.00,95 \%$ CI: 0.54 to 1.88 ). No differences between groups were observed with respect to stent thrombosis up to two years, as summarised in Table 4.

Risks of MACE and its individual components at two years stratified by gender are summarised in Figure 2 and Figure 3. Female high-risk SIHD patients had a higher risk of MACE compared with female ACS patients at two years, whereas the risk of MACE was similar among male high-risk SIHD and ACS patients. However, formal tests for interaction were negative ( $p$-interaction $=0.22$ ).
Noteworthy, female high-risk SIHD patients had a higher risk of MI compared with female ACS patients (OR 2.80, 95\% CI: 1.644.79), whereas no differences were noted among male patients (OR $1.25,95 \%$ CI: $0.86-1.82$ ) with formal tests for interaction resulting as positive (p-interaction $=0.012$ ).

Sensitivity analyses showed that differences disadvantaging highrisk SIHD compared with ACS patients with respect to MACE (OR 1.23, 95\% CI: 0.97-1.55) and MI (OR 0.85, 95\% CI: 0.51-1.43) at two years were no longer evident by excluding periprocedural MI.

\section{Discussion}

This individual patient data pooled analysis of three large contemporary trials including all-comer patients undergoing PCI with the unrestricted use of drug-eluting stents has the following findings:

Table 2. Baseline angiographic characteristics.

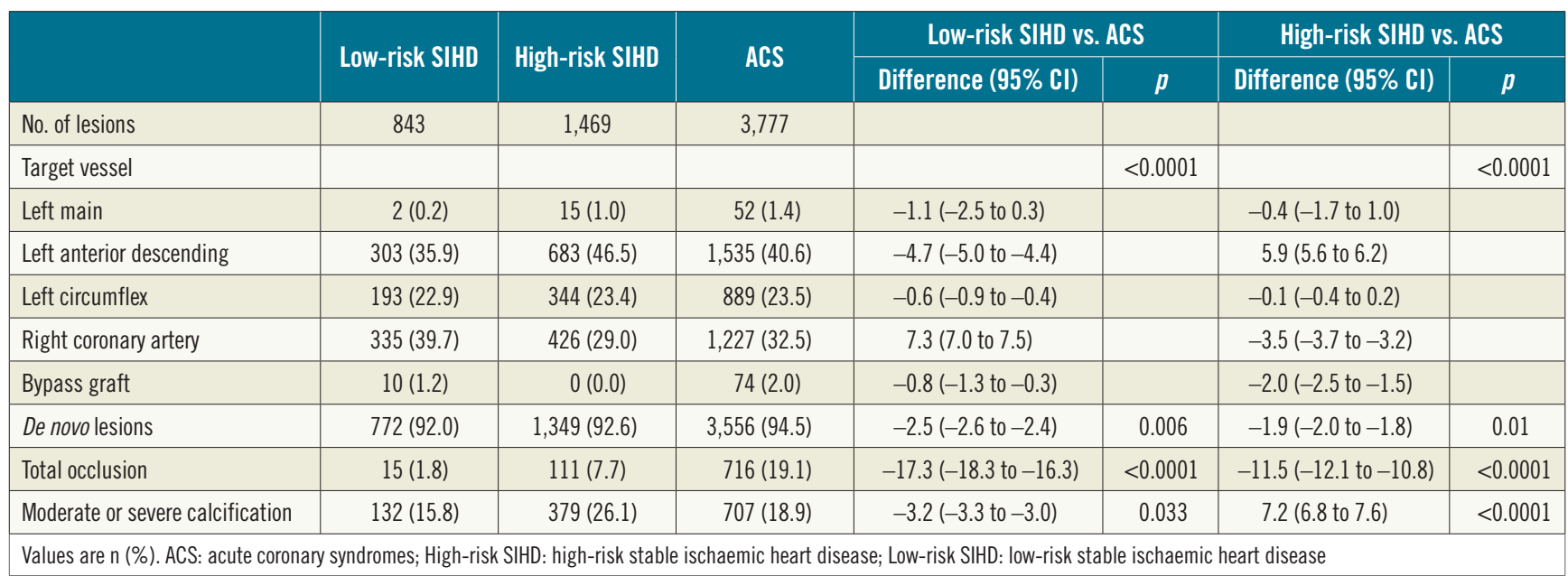


Table 3. Clinical outcomes up to 2 years.

\begin{tabular}{|c|c|c|c|c|c|c|c|}
\hline & \multirow{2}{*}{$\begin{array}{c}\text { Low-risk SIHD } \\
\quad(\mathrm{N}=531)\end{array}$} & \multirow{2}{*}{$\begin{array}{l}\text { High-risk SIHD } \\
\qquad(\mathrm{N}=1,066)\end{array}$} & \multirow{2}{*}{$\begin{array}{c}\text { ACS } \\
(\mathrm{N}=2,607)\end{array}$} & \multicolumn{2}{|c|}{ Low-risk SIHD vs. ACS } & \multicolumn{2}{|c|}{ High-risk SIHD vs. ACS } \\
\hline & & & & OR (95\% CI) & $p$ & OR (95\% CI) & $p$ \\
\hline \multicolumn{8}{|l|}{ Overall } \\
\hline Death & $12(2.3)$ & $33(3.1)$ & $112(4.3)$ & 0.47 (0.26 to 0.87 ) & 0.015 & 0.70 (0.47 to 1.04 ) & 0.081 \\
\hline Cardiac death & $4(0.8)$ & $26(2.4)$ & $81(3.1)$ & 0.22 (0.08 to 0.59 ) & 0.003 & 0.77 (0.49 to 1.21 ) & 0.261 \\
\hline Ml & $20(3.8)$ & $75(7.0)$ & $115(4.4)$ & 0.85 (0.52 to 1.38$)$ & 0.515 & 1.64 (1.21 to 2.21$)$ & 0.001 \\
\hline Ischaemia-driven TVR & $29(5.5)$ & $91(8.5)$ & $183(7.0)$ & 0.68 (0.45 to 1.02$)$ & 0.062 & 1.23 (0.95 to 1.61$)$ & 0.118 \\
\hline Ischaemia-driven TLR & $24(4.5)$ & $75(7.0)$ & $153(5.9)$ & 0.66 (0.42 to 1.03$)$ & 0.070 & 1.21 (0.91 to 1.62$)$ & 0.192 \\
\hline Cardiac death or Ml & $21(4.0)$ & $94(8.8)$ & $179(6.9)$ & 0.54 (0.34 to 0.86$)$ & 0.009 & 1.31 (1.01 to 1.70$)$ & 0.043 \\
\hline MACE & $39(7.3)$ & $148(13.9)$ & $280(10.7)$ & 0.61 (0.43 to 0.87$)$ & 0.006 & 1.34 (1.08 to 1.66$)$ & 0.008 \\
\hline \multicolumn{8}{|l|}{0 to 30 days } \\
\hline Death & $0(0.0)$ & $5(0.5)$ & $25(1.0)$ & 0.00 & 0.994 & 0.48 (0.18 to 1.25$)$ & 0.132 \\
\hline Cardiac death & $0(0.0)$ & $5(0.5)$ & $20(0.8)$ & 0.00 & 0.978 & 0.60 (0.22 to 1.60$)$ & 0.306 \\
\hline MI & $15(2.8)$ & $61(5.7)$ & $81(3.1)$ & 0.94 (0.54 to 1.65$)$ & 0.839 & 1.89 (1.35 to 2.66$)$ & 0.001 \\
\hline Ischaemia-driven TVR & $5(0.9)$ & $19(1.8)$ & $48(1.8)$ & 0.48 (0.19 to 1.21$)$ & 0.121 & 0.97 (0.57 to 1.66$)$ & 0.920 \\
\hline Ischaemia-driven TLR & $4(0.8)$ & $17(1.6)$ & $45(1.7)$ & 0.40 (0.14 to 1.13$)$ & 0.083 & 0.93 (0.53 to 1.63$)$ & 0.792 \\
\hline Cardiac death or Ml & $15(2.8)$ & $64(6.0)$ & $98(3.8)$ & 0.76 (0.44 to 1.32 ) & 0.332 & 1.63 (1.18 to 2.26 ) & 0.003 \\
\hline MACE & $16(3.0)$ & $71(6.7)$ & $113(4.3)$ & 0.70 (0.41 to 1.19$)$ & 0.182 & 1.57 (1.16 to 2.14) & 0.004 \\
\hline \multicolumn{8}{|l|}{31 days to 2 years } \\
\hline Death & $12(2.3)$ & $28(2.6)$ & $87(3.3)$ & 0.61 (0.33 to 1.13) & 0.119 & 0.77 (0.50 to 1.19) & 0.247 \\
\hline Cardiac death & $4(0.8)$ & $21(2.0)$ & $61(2.3)$ & 0.29 (0.10 to 0.80$)$ & 0.017 & 0.84 (0.51 to 1.38 ) & 0.482 \\
\hline MI & $5(0.9)$ & $14(1.3)$ & $34(1.3)$ & 0.65 (0.25 to 1.68$)$ & 0.376 & 1.00 (0.54 to 1.88$)$ & 0.988 \\
\hline Ischaemia-driven TVR & $24(4.5)$ & $72(6.8)$ & $135(5.2)$ & 0.76 (0.48 to 1.19$)$ & 0.226 & 1.32 (0.98 to 1.78 ) & 0.067 \\
\hline Ischaemia-driven TLR & $20(3.8)$ & $58(5.4)$ & $108(4.1)$ & 0.78 (0.48 to 1.27 ) & 0.316 & 1.33 (0.95 to 1.85 ) & 0.093 \\
\hline Cardiac death or Ml & $6(1.1)$ & $30(2.8)$ & $81(3.1)$ & 0.32 (0.14 to 0.74$)$ & 0.007 & 0.90 (0.59 to 1.38) & 0.628 \\
\hline MACE & $23(4.3)$ & $77(7.2)$ & $167(6.4)$ & $0.58(0.37$ to 0.90$)$ & 0.016 & 1.13 (0.86 to 1.50$)$ & 0.382 \\
\hline
\end{tabular}

Values are $n$ (\%). ACS: acute coronary syndromes; Cl: confidence interval; High-risk SIHD: high-risk stable ischaemic heart disease; Low-risk SIHD: low-risk stable ischaemic heart disease; MACE: major adverse cardiac events; MI: myocardial infarction; OR: odds ratio; TLR: target lesion revascularisation; TVR: target vessel revascularisation

1. Patients with SIHD had a high baseline angiographic risk estimate in up to two thirds of cases.

2. High-risk SIHD patients showed a higher risk of MACE compared with ACS patients up to two years of follow-up, mainly due to a higher risk of MI occurring within the first 30 days after PCI.
3. The increased risk of MI was particularly pronounced among female high-risk SIHD patients.

4. Excluding MI within the first 30 days after PCI, the risk of MI was similar among high-risk SIHD and ACS patients up to two years.

Table 4. Stent thrombosis up to 2 years.

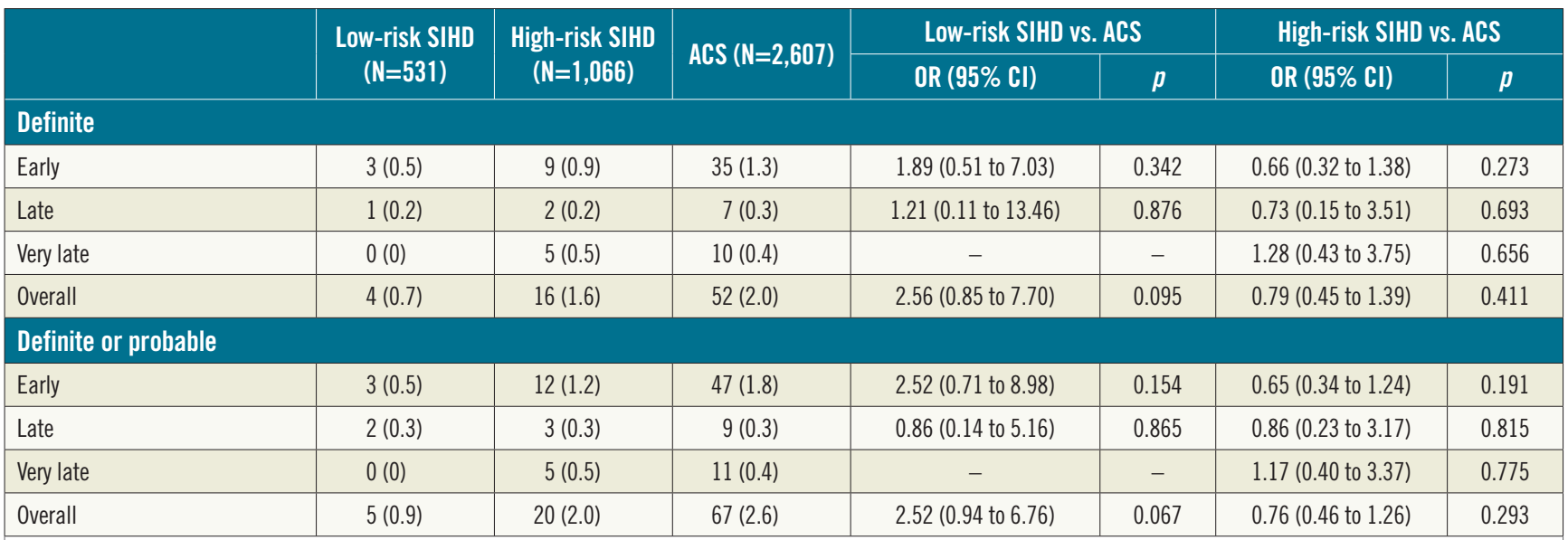

Values are $\mathrm{n}(\%)$. ACS: acute coronary syndromes; Cl: confidence interval; High-risk SIHD: high-risk stable ischaemic heart disease; Low-risk SIHD:

low-risk stable ischaemic heart disease; OR: odds ratio 


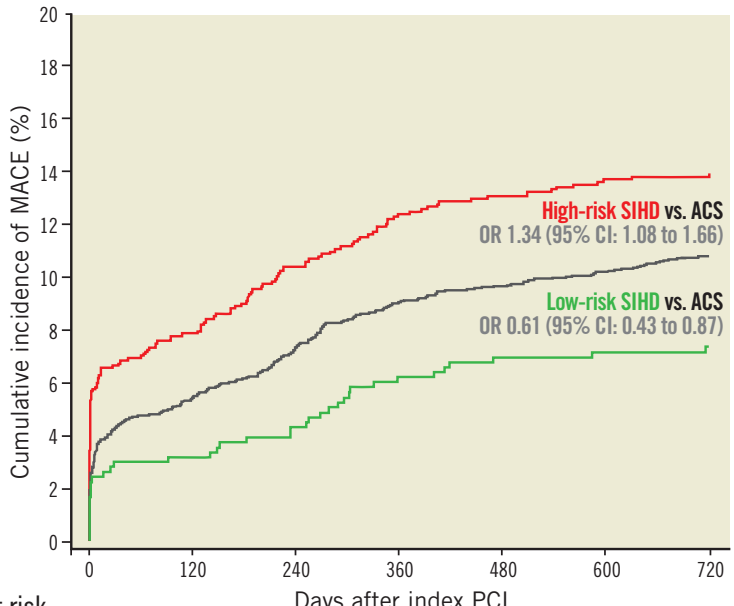

No. at risk

$\begin{array}{rrrrrrrr}\text { SHR } & 1,066 & 980 & 952 & 929 & 920 & 913 & 700 \\ \text { ACS } & 2,607 & 2,457 & 2,404 & 2,355 & 2,336 & 2,319 & 1,813 \\ \text { SLR } & 531 & 513 & 506 & 495 & 491 & 489 & 400\end{array}$

Figure 1. Major adverse cardiac events up to 2 years. Cumulative incidence curves of the main outcome measure MACE up to 2 years of follow-up. ACS: acute coronary syndromes; CI: confidence interval; High-risk SIHD: high-risk stable ischaemic heart disease; Low-risk SIHD: low-risk stable ischaemic heart disease; OR: odds ratio; SHR: stable high-risk; SLR: stable low-risk

Patients undergoing PCI for ACS are regarded as a group at increased risk of further cardiac ischaemic events ${ }^{25}$ and have been excluded from early trials investigating DES. More recent randomised studies investigating the unrestricted use of DES applied an all-comers design, therefore extending recruitment also to ACS patients (including non-ST-elevation and ST-elevation ACS) ${ }^{8-11}$.

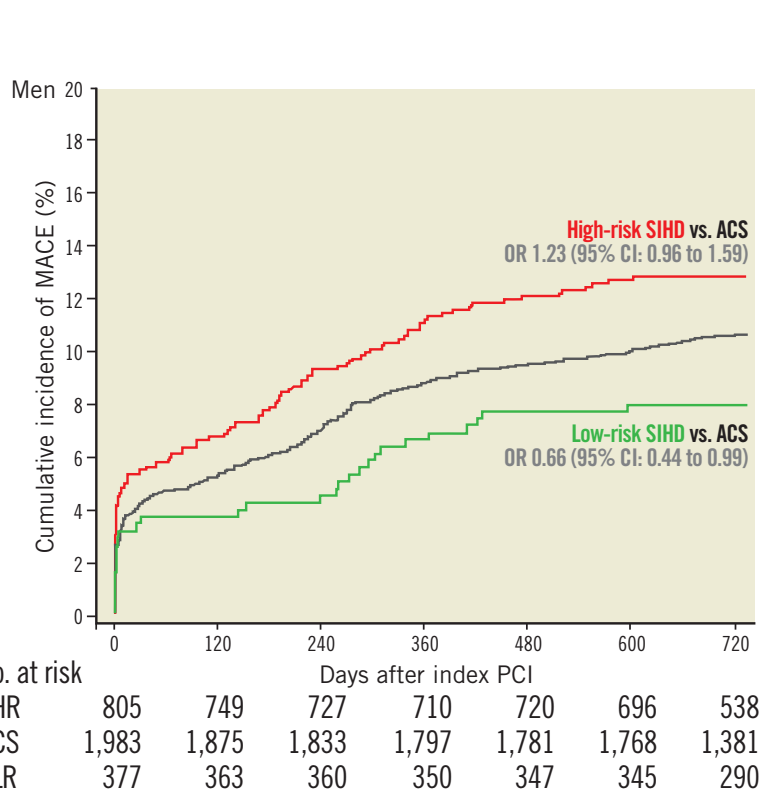

The SIRTAX, LEADERS, and RESOLUTE-AC trials, pooled in this individual patient data analysis, are three large all-comers trials more closely representing treatment in routine clinical practice ${ }^{9-11}$. Noteworthy, rates of death of ACS patients included in this pooled analysis (4.3\%) were comparable with those observed in contemporary ACS trials such as TRITON-TIMI $38^{15}(3.0 \%)$ and PLATO $^{26}(4.5 \%)$, underscoring the representative nature of the present patient population.

Our findings indicate that a substantial proportion of patients with SIHD undergoing elective PCI have a higher risk of MACE compared with ACS patients at 30 days and two years of followup. Although the difference was mainly due to periprocedural MI, it is interesting that, by excluding the latter high-risk SIHD patients, a similar risk of MACE compared with ACS patients was maintained. This result points to the fact that high-risk SIHD patients need to be considered as being at least at similar risk to ACS patients, and that they might benefit from more intense pharmacotherapy and secondary prevention currently reserved to ACS patients. High-risk SIHD patients have not been investigated in dedicated randomised clinical trials, and therefore there are limited grounds for evidence-based treatment guidelines and the potential for undertreatment.

In our study, high-risk SIHD patients and ACS patients differed in baseline clinical and angiographic characteristics, underlining a different coronary atherosclerotic burden. Therefore, the pathophysiologic mechanisms leading to the increased risk of MACE in high-risk SIHD patients and ACS patients might differ. While the importance of an aggressive risk factor management is expected to be critical for both groups, the therapeutic impact of adjunctive and preventive pharmacotherapy remains speculative and needs to be addressed in future studies.

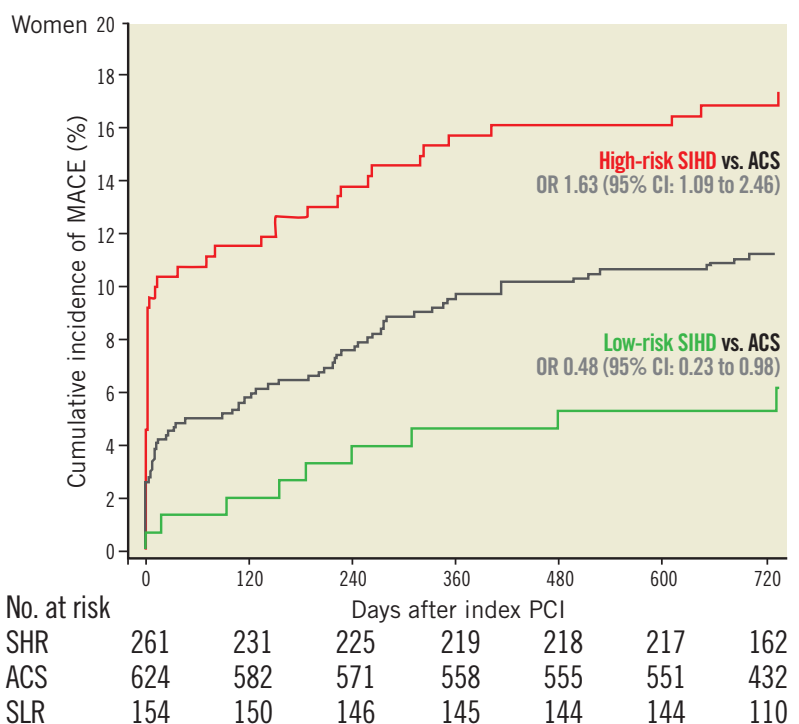

Figure 2. Major adverse cardiac events up to 2 years stratified by gender. Cumulative incidence curves of the main outcome measure MACE up to 2 years of follow-up. ACS: acute coronary syndromes; CI: confidence interval; High-risk SIHD: high-risk stable ischaemic heart disease; Low-risk SIHD: low-risk stable ischaemic heart disease; OR: odds ratio; SHR: stable high-risk; SLR: stable low-risk 


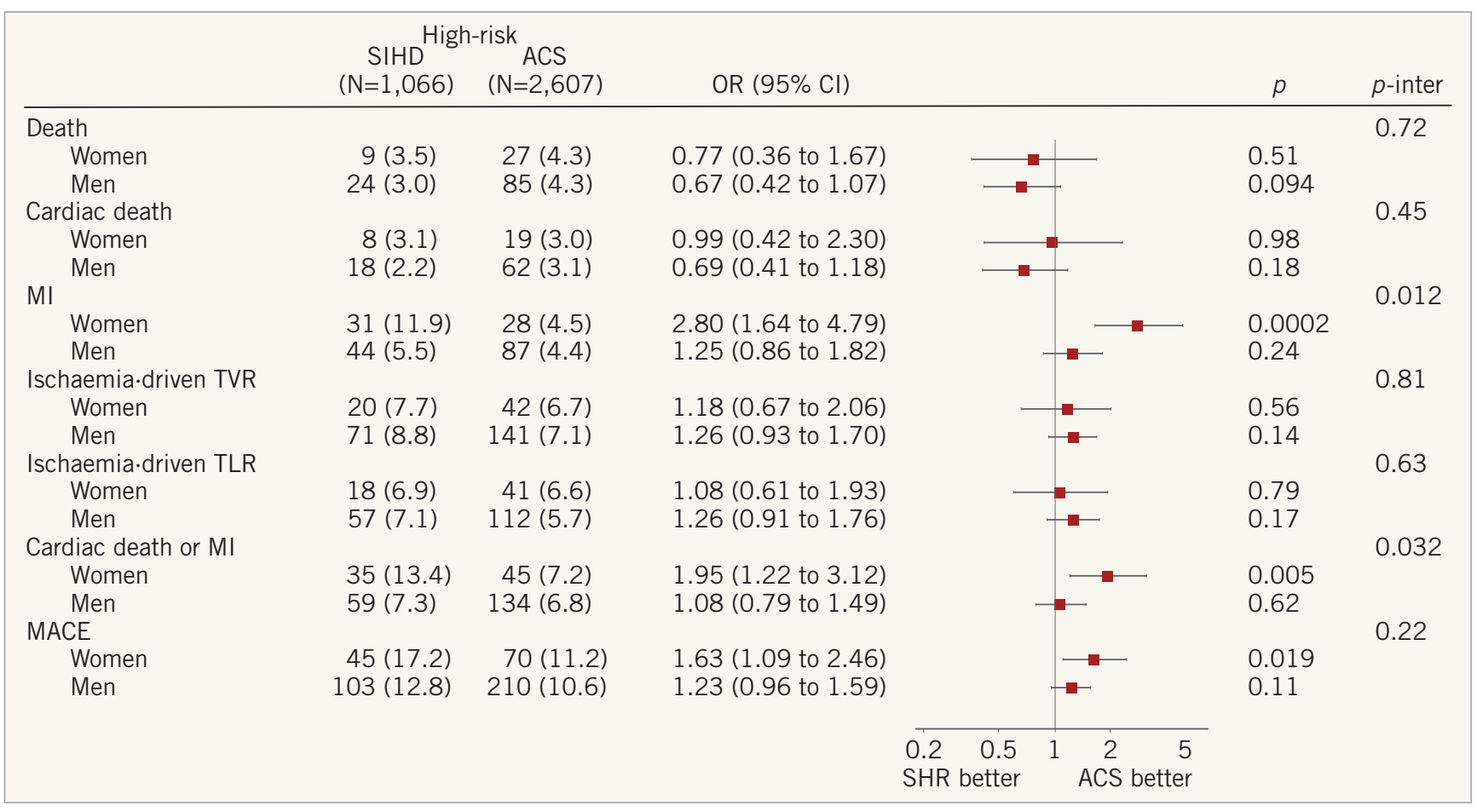

Figure 3. Risks of MACE and its individual components at 2 years stratified by gender. ACS: acute coronary syndromes; CI: confidence interval; High-risk SIHD: high-risk stable ischaemic heart disease; OR: odds ratio; SHR: stable high-risk; TLR: target lesion revascularisation; TVR: target vessel revascularisation

The key difference in MACE as it relates to periprocedural MI observed in our analysis raises two relevant issues. First, the adjudication of periprocedural MI is difficult in ACS patients due to the elevated preprocedural cardiac biomarkers. The critical challenge is to distinguish whether a new cardiac biomarker elevation is induced by the PCI procedure (e.g., extension of ischaemia, new procedural flow-limiting complications, etc.) or if the cardiac biomarker release is the tail of the ongoing initial insult ${ }^{27}$. Second, the clinical relevance of periprocedural MI remains problematic. In the three trials pooled in this analysis, the MI definition was based on CK-MB, which is less sensitive than troponins; however, the threshold used for MI definition was relatively low. Post-procedural cardiac biomarker elevation is more debated. To date, there is no evidence of impaired long-term clinical outcomes among SIHD patients with post-procedural cardiac biomarker elevation without symptoms or electrocardiographic signs of ischaemia ${ }^{27}$. Noteworthy, the recently released revised version of the universal definition of MI document recommends a postprocedural threshold higher than the one used in our study (i.e., $5 \mathrm{x}$ upper reference limit) ${ }^{25}$.

Of note, the excessive risk of MI was particularly pronounced among female high-risk SIHD patients compared with female ACS patients, whereas no significant difference among male patients was noted. The observed positive interaction suggests that this difference is above that which might have been expected by chance alone. A sex-related difference in response to procedural triggers of myocardial injury may be possible. Nevertheless, this finding needs to be cautiously interpreted in the light of its observational nature as well as the debated clinical relevance of post-procedural cardiac biomarker elevation ${ }^{28}$.

\section{Limitations}

This analysis has a number of limitations. First, it is a post hoc analysis of trials not primarily intended to investigate differences based on clinical indication for PCI. However, the large size, the all-comers nature of the study population, and the core-lab assessment of baseline characteristics provide a unique opportunity to compare outcomes of ACS patients with those of SIHD patients. Second, the relatively low event rates make our findings prone to chance. However, these rates are consistent with real-world contemporary clinical practice. Moreover, the observation that the cumulative risk of MACE and its individual components among the different groups point in the same direction supports the robustness of our findings. Third, this post hoc analysis was not powered for multiple effects modification. Therefore, our findings must be regarded as exploratory and hypothesis-generating until confirmed by evidence from rigorously conducted prospective randomised trials.

\section{Conclusions}

In this pooled analysis of three large contemporary trials the majority of patients undergoing elective PCI for SIHD had a higher risk of MACE than patients with ACS during long-term follow-up. This was primarily due to a higher risk of MI among high-risk SIHD patients during the first 30 days, and was particularly pronounced among female high-risk SIHD patients. 


\section{Impact on daily practice}

There is an unmet need in primary and secondary cardiovascular prevention. Ultimately PCI should open the door towards optimising secondary prevention. The SYNTAX (SX-) score, based on simple baseline angiographic criteria, predicts procedural risk and annual rates of major adverse cardiovascular events among patients undergoing PCI. Up to two thirds of patients undergoing PCI for SIHD (SX-score >8) in routine clinical practice have a higher risk of MACE than ACS patients. It remains to be determined whether they would benefit from more intensive anti-platelet therapy.

\section{Guest Editor}

This paper was guest edited by Ron Waksman, MD; Interventional Cardiology, MedStar Washington Hospital Center, Washington, DC, USA.

\section{Funding}

The SIRTAX trial was supported by research grants from Bern University Hospital (757) and University Hospital Zurich (3303). The LEADERS trial was supported by Biosensors Europe SA, Switzerland. The RESOLUTE-AC trial was supported by Medtronic Vascular Inc., Santa Rosa, CA, USA. The statistical analysis was funded by intramural grants provided by CTU Bern, Bern University Hospital, the Institute of Social and Preventive Medicine, University of Bern, and the Swiss National Science Foundation (SPUM, grant 33CM30-140336). The individual trial sponsors had no role in the design, data analysis, data interpretation, or writing of this report.

\section{Conflict of interest statement}

CTU Bern, which is part of the University of Bern, has a staff policy of not accepting honoraria or consultancy fees. P. Jüni is an unpaid steering committee or statistical executive member of trials funded by Abbott Vascular, Biosensors, Medtronic and Cordis. $\mathrm{S}$. Windecker has received research contracts to the institution from Abbott Vascular, Boston Scientific, Biosensors, Cordis, Medtronic and St. Jude Medical. All other authors report no conflicts of interest. The Guest Editor received grant support from Lilly Daiichi and AstraZeneca. He is also a speaker for AstraZeneca.

\section{References}

1. Boden WE, O'Rourke RA, Teo KK, Hartigan PM, Maron DJ, Kostuk WJ, Knudtson M, Dada M, Casperson P, Harris CL, Chaitman BR, Shaw L, Gosselin G, Nawaz S, Title LM, Gau G, Blaustein AS, Booth DC, Bates ER, Spertus JA, Berman DS, Mancini GB, Weintraub WS; COURAGE Trial Research Group. Optimal medical therapy with or without PCI for stable coronary disease. N Engl J Med. 2007;356:1503-16.

2. Tonino PA, De Bruyne B, Pijls NH, Siebert U, Ikeno F, van' t Veer M, Klauss V, Manoharan G, Engstrøm T, Oldroyd KG, Ver Lee PN, MacCarthy PA, Fearon WF; FAME Study Investigators.
Fractional flow reserve versus angiography for guiding percutaneous coronary intervention. $N$ Engl J Med. 2009;360:213-24.

3. Serruys PW, De Jaegere P, Kiemenij F, Macaya C, Rutsch W, Heyndrickx G, Emanuelsson H, Marco J, Legrand V, Materne P, Belardi J, Sigwart U, Colombo A, Goy J, van den Heuvel P, Delcan J, Morel M. A comparison of balloon-expandable-stent implantation with balloon angioplasty in patients with coronary artery disease. Benestent Study Group. N Engl J Med. 1994;331: 489-95.

4. De Bruyne B, Pijls NH, Kalesan B, Barbato E, Tonino PA, Piroth Z, Jagic N, Mobius-Winckler S, Rioufol G, Witt N, Kala P, MacCarthy $P$, Engström $T$, Oldroyd KG, Mavromatis $K$, Manoharan G, Verlee P, Frobert O, Curzen N, Johnson JB, Jüni P, Fearon WF; FAME 2 Trial Investigators. Fractional flow reserveguided PCI versus medical therapy in stable coronary disease. N Engl J Med. 2012;367:991-1001.

5. Kappetein AP, Dawkins KD, Mohr FW, Morice MC, Mack MJ, Russell ME, Pomar J, Serruys PW. Current percutaneous coronary intervention and coronary artery bypass grafting practices for three-vessel and left main coronary artery disease. Insights from the SYNTAX run-in phase. Eur J Cardiothorac Surg. 2006;29:486-91.

6. Serruys PW, Morice MC, Kappetein AP, Colombo A, Holmes DR, Mack MJ, Ståhle E, Feldman TE, van den Brand M, Bass EJ, Van Dyck N, Leadley K, Dawkins KD, Mohr FW; SYNTAX Investigators. Percutaneous coronary intervention versus coronary-artery bypass grafting for severe coronary artery disease. N Engl J Med. 2009;360:961-72.

7. Stefanini GG, Serruys PW, Silber S, Khattab AA, van Geuns RJ, Richardt G, Buszman PE, Kelbæk H, van Boven AJ, Hofma SH, Linke A, Klauss V, Wijns W, Macaya C, Garot P, Di Mario C, Manoharan G, Kornowski R, Ischinger T, Bartorelli AL, Gobbens P, Windecker S. The impact of patient and lesion complexity on clinical and angiographic outcomes after revascularization with zotarolimus- and everolimus-eluting stents: a substudy of the RESOLUTE All Comers Trial (a randomized comparison of a zotarolimus-eluting stent with an everolimus-eluting stent for percutaneous coronary intervention). $J$ Am Coll Cardiol. 2011;57:2221-32.

8. Kedhi E, Joesoef KS, McFadden E, Wassing J, van Mieghem C, Goedhart D, Smits PC. Second-generation everolimus-eluting and paclitaxel-eluting stents in real-life practice (COMPARE): a randomised trial. Lancet. 2010;375:201-9.

9. Windecker S, Remondino A, Eberli FR, Jüni P, Räber L, Wenaweser P, Togni M, Billinger M, Tüller D, Seiler C, Roffi M, Corti R, Sütsch G, Maier W, Lüscher T, Hess OM, Egger M, Meier B. Sirolimus-eluting and paclitaxel-eluting stents for coronary revascularization. $N$ Engl J Med. 2005;353:653-62.

10. Windecker S, Serruys PW, Wandel S, Buszman P, Trznadel S, Linke A, Lenk K, Ischinger T, Klauss V, Eberli F, Corti R, Wijns W, Morice MC, di Mario C, Davies S, van Geuns RJ, Eerdmans P, van Es GA, Meier B, Jüni P. Biolimus-eluting stent with biodegradable polymer versus sirolimus-eluting stent with durable polymer for coronary revascularisation (LEADERS): a randomised non-inferiority trial. Lancet. 2008;372:1163-73. 
11. Serruys PW, Silber S, Garg S, van Geuns RJ, Richardt G, Buszman PE, Kelbaek H, van Boven AJ, Hofma SH, Linke A, Klauss V, Wijns W, Macaya C, Garot P, DiMario C, Manoharan G, Kornowski R, Ischinger T, Bartorelli A, Ronden J, Bressers M, Gobbens P, Negoita M, van Leeuwen F, Windecker S. Comparison of zotarolimus-eluting and everolimus-eluting coronary stents. N Engl J Med. 2010;363:136-46.

12. Wijns W, Kolh P, Danchin N, Di Mario C, Falk V, Folliguet T, Garg S, Huber K, James S, Knuuti J, Lopez-Sendon J, Marco J, Menicanti L, Ostojic M, Piepoli MF, Pirlet C, Pomar JL, Reifart N, Ribichini FL, Schalij MJ, Sergeant P, Serruys PW, Silber S, Sousa Uva M, Taggart D. Guidelines on myocardial revascularization: the Task Force on Myocardial Revascularization of the European Society of Cardiology (ESC) and the European Association for Cardio-Thoracic Surgery (EACTS). Eur Heart J. 2010;31:2501-55.

13. Farooq V, Vergouwe Y, Räber L, Vranckx P, Garcia-Garcia H, Diletti R, Kappetein AP, Morel MA, de Vries T, Swart M, Valgimigli M, Dawkins KD, Windecker S, Steyerberg EW, Serruys PW. Combined anatomical and clinical factors for the longterm risk stratification of patients undergoing percutaneous coronary intervention: the Logistic Clinical SYNTAX score. Eur Heart J. 2012;33:3098-104.

14. Garg S, Stone GW, Kappetein AP, Sabik JF 3rd, Simonton C, Serruys PW. Clinical and angiographic risk assessment in patients with left main stem lesions. JACC Cardiovasc Interv. 2010;3:891-901.

15. Wiviott SD, Braunwald E, McCabe $\mathrm{CH}$, Montalescot G, Ruzyllo W, Gottlieb S, Neumann FJ, Ardissino D, De Servi S, Murphy SA, Riesmeyer J, Weerakkody G, Gibson CM, Antman EM; TRITON-TIMI 38 Investigators. Prasugrel versus clopidogrel in patients with acute coronary syndromes. $N$ Engl J Med. 2007;357:2001-15.

16. Sianos G, Morel MA, Kappetein AP, Morice MC, Colombo A, Dawkins K, van den Brand M, Van Dyck N, Russell ME, Mohr FW, Serruys PW. The SYNTAX Score: an angiographic tool grading the complexity of coronary artery disease. EuroIntervention. 2005;1:219-27.

17. Garg S, Sarno G, Girasis C, Vranckx P, de Vries T, Swart M, Bressers M, Garcia-Garcia HM, van Es GA, Räber L, Campo G, Valgimigli M, Dawkins KD, Windecker S, Serruys PW. A patientlevel pooled analysis assessing the impact of the SYNTAX (synergy between percutaneous coronary intervention with taxus and cardiac surgery) score on 1-year clinical outcomes in 6,508 patients enrolled in contemporary coronary stent trials. JACC Cardiovasc Interv. 2011;4:645-53.

18. Cutlip DE, Windecker S, Mehran R, Boam A, Cohen DJ, van Es GA, Steg PG, Morel MA, Mauri L, Vranckx P, McFadden E, Lansky A, Hamon M, Krucoff MW, Serruys PW; Academic Research Consortium. Clinical end points in coronary stent trials: a case for standardized definitions. Circulation. 2007;115:2344-51
19. Vranckx P, Cutlip DE, Mehran R, Kint PP, Silber S, Windecker S, Serruys PW. Myocardial infarction adjudication in contemporary all-comer stent trials: balancing sensitivity and specificity. Addendum to the historical MI definitions used in stent studies. EuroIntervention. 2010;5:871-4.

20. Serruys PW, Onuma Y, Garg S, Sarno G, van den Brand M, Kappetein AP, Van Dyck N, Mack M, Holmes D, Feldman T, Morice MC, Colombo A, Bass E, Leadley K, Dawkins KD, van Es GA, Morel MA, Mohr FW. Assessment of the SYNTAX score in the Syntax study. EuroIntervention. 2009;5:50-6.

21. SYNTAX working-group. SYNTAX score calculator: www. syntaxscore.com. Launched 19th May 2009.

22. Wykrzykowska JJ, Garg S, Girasis C, de Vries T, Morel MA, van Es GA, Buszman P, Linke A, Ischinger T, Klauss V, Corti R, Eberli F, Wijns W, Morice MC, di Mario C, van Geuns RJ, Juni P, Windecker S, Serruys PW. Value of the Syntax Score (SX) for risk assessment in the "all-comers" population of the randomized multicenter Leaders trial. J Am Coll Cardiol. 2010;56:272-7.

23. Girasis C, Garg S, Raber L. Prediction of 5-year clinical outcomes using the SYNTAX score in patients undergoing PCI from the Sirolimus eluting stent compared with paclitaxel eluting stent for coronary revascularisation (SIRTAX) trial. Abstract at American College of Cardiology meeting, March 14-16 ${ }^{\text {th }} 2010$, Atlanta, GA, USA.

24. Magro M, Nauta S, Simsek C, Onuma Y, Garg S, van der Heide E, van der Giessen WJ, Boersma E, van Domburg RT, van Geuns RJ, Serruys PW. Value of the SYNTAX score in patients treated by primary percutaneous coronary intervention for acute ST elevation myocardial infarction - the MI SYNTAXscore study. Am Heart J. 2011;161:771-81.

25. Thygesen K, Alpert JS, Jaffe AS, Simoons ML, Chaitman BR, White HD for the Writing Group on behalf of the Joint ESC/ACCF/ AHA/WHF Task Force for the Universal Definition of Myocardial Infarction. Third universal definition of myocardial infarction. Eur Heart J. 2012;33:2551-67.

26. Cannon CP, Harrington RA, James S, Ardissino D, Becker RC, Emanuelsson H, Husted S, Katus H, Keltai M, Khurmi NS, Kontny F, Lewis BS, Steg PG, Storey RF, Wojdyla D, Wallentin L; PLATelet inhibition and patient Outcomes Investigators. Comparison of ticagrelor with clopidogrel in patients with a planned invasive strategy for acute coronary syndromes (PLATO): a randomised double-blind study. Lancet. 2010;375:283-93.

27. Vranckx P, Farooq V, Garg S, Van Es GA, Silber S, Windecker S, Stone GW, Serruys PW. Different cardiac biomarkers to detect peri-procedural myocardial infarction in contemporary coronary stent trials: impact on outcome reporting. Heart. 2012;98:1424-30.

28 Wang R, Lagakos SW, Ware JH, Hunter DJ, Drazen JM. Statistics in medicine--reporting of subgroup analyses in clinical trials. N Engl J Med. 2007;357:2189-94. 